\title{
Planning for Mental Health Needs During COVID-19
}

\author{
Rachel H. Han ${ }^{1} \cdot$ Morgan N. Schmidt ${ }^{2} \cdot$ Wendi M. Waits ${ }^{1} \cdot$ Alexa K. C. Bell ${ }^{3} \cdot$ Tashina L. Miller $^{1}$ \\ Accepted: 17 September 2020 / Published online: 8 October 2020 \\ (C) This is a U.S. government work and not under copyright protection in the U.S.; foreign copyright protection may apply 2020
}

\begin{abstract}
Purpose of Review The ability to effectively prepare for and respond to the psychological fallout from large-scale disasters is a core competency of military mental health providers, as well as civilian emergency response teams. Disaster planning should be situation specific and data driven; vague, broad-spectrum planning can contribute to unprepared mental health teams and underserved patient populations. Herein, we review data on mental health sequelae from the twenty-first century pandemics, including SARS-CoV2 (COVID-19), and offer explanations for observed trends, insights regarding anticipated needs, and recommendations for preliminary planning on how to best allocate limited mental health resources.

Recent Findings Anxiety and distress, often attributed to isolation, were the most prominent mental health complaints during previous pandemics and with COVID-19. Additionally, post-traumatic stress was surprisingly common and possibly more enduring than depression, insomnia, and alcohol misuse. Predictions regarding COVID-19's economic impact suggest that depression and suicide rates may increase over time.

Summary Available data suggest that the mental health sequelae of COVID-19 will mirror those of previous pandemics. Clinicians and mental health leaders should focus planning efforts on the negative effects of isolation, particularly anxiety and distress, as well as post-traumatic stress symptoms.
\end{abstract}

Keywords Disaster psychiatry $\cdot$ Mental health $\cdot$ Pandemics $\cdot$ COVID-19 $\cdot$ Data-informed planning

\section{Introduction}

Although the coronavirus (COVID-19) pandemic initially resulted in roughly 1000 new COVID-19-related listings each week on the PubMed.gov website, very few of these publications addressed the practical matter of how mental health providers and leaders should specifically plan for the post-pandemic mental health tsunami that many predict is inevitable [1]. The purpose of this article, written from the perspective of military medical planners, is to present available data on the prevalence of specific mental health concerns

This article is part of the Topical collection on Military Mental Health

Rachel H. Han

rachelhyeun@gmail.com

1 Walter Reed National Military Medical Center, Behavioral Health Consultation and Education, 8960 Brown Drive, Building 7 Room 5309, Bethesda, MD 20889, USA

2 Naval Medical Center San Diego, San Diego, CA, USA

3 Uniformed Services University of the Health Sciences, Bethesda, MD, USA and conditions from previous recent pandemics and COVID19 , as well as to provide data-informed recommendations for meeting the psychological needs of affected individuals.

\section{Background}

Historically, pandemics have had significant ramifications for psychological stress and mental health. The global reach and protracted course are unique to pandemics and other infectious disease outbreaks compared with other types of disasters. Prolonged social distancing protocols, increased unemployment rates, and economic stress have the potential to create an unprecedented mental health crisis. From prior disasters, military researchers have learned that affected people tend to do well over time with minimal psychiatric sequelae $[2 \bullet \bullet]$. However, there is still concern for residual psychopathology, including anxiety, depression, bereavement, and posttraumatic stress. Among healthcare workers $(\mathrm{HCWs})$ in particular, decreased social support and isolation may be expected even while at work due to assignment to unfamiliar hospital areas, requirement for personal protective equipment (PPE) that obscures identities, and inability to gather in groups [3••]. 
Physical distancing, while important to protect against physical illness, often results in social isolation and loneliness, especially for vulnerable groups. It is well known that social isolation has a detrimental effect on mental health outcomes. Both living alone and feelings of loneliness have been associated with increased suicidal ideation and suicide attempt [4]. Further, since COVID-19 was declared a public health emergency, many employees have been either laid off or furloughed, causing economic anxiety and distress. Many schools and daycares have also physically closed indefinitely, forcing families with children to take time off from work to provide childcare and take on the additional burden of assisting with virtual learning. In the past, times of economic downturn have been associated with increased rates of completed suicide in high-income countries [5]. Accordingly, we anticipate a rise in mental healthcare usage and increased susceptibility of certain groups to mental illness and its consequences as the pandemic continues.

\section{Methods}

\section{Study Design}

We conducted a rapid review of the twenty-first-century pandemics with the goal of establishing a preliminary projection of mental health needs related to COVID-19. Since formal Preferred Reporting Items for Systematic Reviews and Meta-Analyses (PRISMA) guidance for rapid reviews is currently pending, we referred to a published analysis of the most common rapid review elements while conducting our review [6-8]. Questions we hoped to answer included the following: What mental health sequelae emerged following pre-COVID19 twenty-first-century pandemics? and What does preliminary data on the psychological effects of COVID-19 reveal? Our rapid review included papers published from January 2002 to July 2020 on PubMed, as well as searches of various gray literature sources for guidelines, position papers, and journalistic reports. Search strategies were structured around three major concepts: pandemics, mental health, and data analysis.

\section{Data Collection}

A combination of the following keywords in the title and/or abstract was used in searches of literature on the Southeast Asian Respiratory Syndrome (SARS), H1N1 influenza (H1N1), Middle Eastern Respiratory Syndrome (MERS), Ebola, and COVID-19 pandemics: mental health OR mental illness OR psychiatry OR psychology OR therapist OR PTSD OR posttraumatic OR post-traumatic stress disorder OR behavioral health OR anxiety [disorder] OR GAD OR depression/depressed OR complex grief AND data analysis OR statistic* OR prevalence OR percentage OR increase OR decrease.

\section{Inclusion and Exclusion Criteria}

Peer-reviewed articles addressing the mental health sequelae during or following the listed pandemics were included. Other inclusion criteria were populations of all age groups, from any location, and published in English. Articles that reported physical health rather than mental health were excluded. Articles that reported on preventative behaviors were also excluded. Additional exclusion criteria included case studies, abstracts, commentaries, and opinion pieces. Titles and abstracts of the identified literature were first reviewed. Literature not complying with the search criteria was excluded. The full text was obtained for articles in which inclusion/exclusion criteria were not clear, and references were independently screened.

\section{Results}

The findings presented chronologically below are based on information pertaining to recent pandemics, including Severe Acute Respiratory Syndrome (SARS), 2009 H1N1 influenza virus (H1N1), Middle Eastern Respiratory Syndrome (MERS), Ebola, as well as the current COVID-19 pandemic (see Fig. 1). Findings for children pertaining to COVID-19 are discussed separately given the unique psychological conditions considered for this population.

\section{SARS}

The SARS coronavirus epidemic spread through 26 countries in 2003, resulting in over 8000 cases, largely affecting Asian countries. Community-based surveys revealed that during the outbreak, almost $40 \%$ of community populations experienced increased stress, with $17 \%$ experiencing post-traumatic stress symptoms [9]. A Taiwan-based study showed $11.7 \%$ of a nationwide sample had a psychiatric morbidity measured by the Brief Symptoms Rating Scale [10]. HCWs were also significantly affected due to risk of exposure, with higher ratings of stress and depressive and anxious symptoms persisting a year post-outbreak [9]. Six percent self-medicated with alcohol to cope with these feelings [11]. Having to quarantine also caused a significant increase in depressive symptoms [12]. Nonetheless, no rise in DSM-IV psychiatric diagnosis was found 2 years later [13].

Elderly populations appeared to be at greater risk of suicide, with a $31 \%$ increase in completed suicides among adults aged 65 and older in Hong Kong in 2003 at the peak of SARS cases. Further analysis led to identification of certain factors, including fear of contracting SARS, increased isolation, disruption of social life, and increased chronic disease burden 
Fig. 1 Flow diagram for review of pandemic mental health outcomes

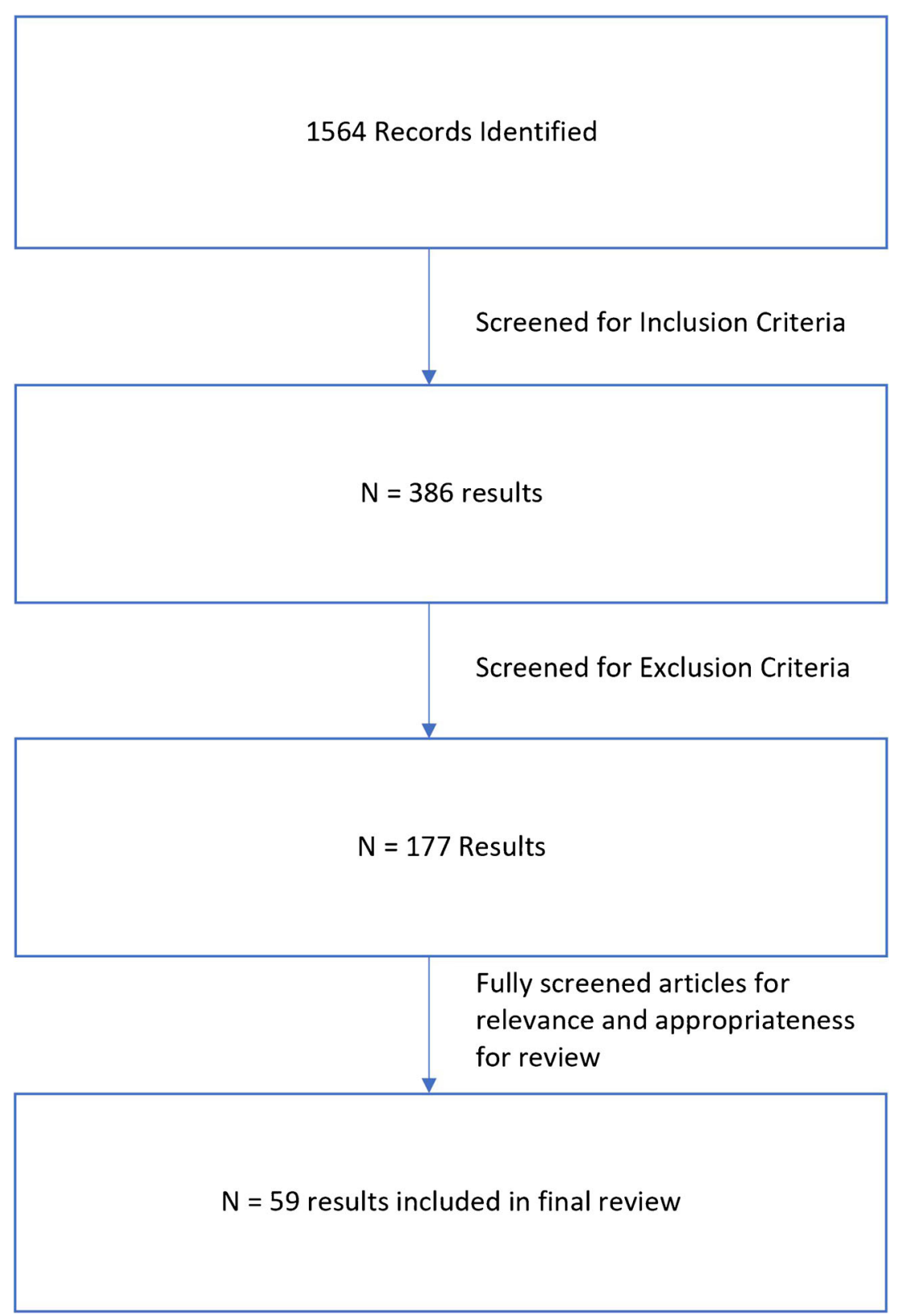

[14]. Finally, survivors had significant levels of psychiatric morbidity after the epidemic. Prevalence of any psychiatric disorder at long-term follow-up was 33-42.5\%, with $25 \%$ of survivors carrying a diagnosis of post-traumatic stress disorder (PTSD) and 15\% having a depressive disorder $[15,16]$.

\section{H1N1}

In the USA, the H1N1 influenza virus was first detected in April 2009. By April 2010, the Centers for Disease Control and Prevention (CDC) estimated about 60.8 million cases, 274,304 hospitalizations, and 12,469 deaths due to the virus in the USA alone. The published data on behavioral/ psychological responses focuses mostly on the anxiety prevalent due to uncertain conditions among HCWs [17].

In Guangzhou, China, $10.7 \%$ of university students reported feeling panicked, depressed, or emotionally disturbed as a result of $\mathrm{H} 1 \mathrm{~N} 1$, and $45 \%$ worried about them or their family catching the virus [18]. HCWs in Greece experienced moderately high anxiety about the pandemic, with their predominate concern being infection of family and friends and subsequent health consequences. Interestingly, perceived sufficiency of public information about $\mathrm{H} 1 \mathrm{~N} 1$ was associated with reduced degree of worry [19]. This finding was consistent with findings among HCWs in Japan, where workers who were less frequently provided information about the pandemic felt less protected than their more informed colleagues. In addition, 
Japanese hospital workers in higher risk environments felt more anxious and exhausted [20].

\section{MERS}

The Middle East Respiratory Syndrome (MERS) first emerged in Saudi Arabia in 2012 and spread throughout the Arabian Peninsula, affecting over 2000 individuals. While person-to-person transmission was limited, HCWs were deemed to be at higher risk for contracting MERS, with a case fatality rate of around $30-40 \%$. A South Korean study of 1656 quarantined individuals showed $7.6 \%$ had feelings of anxiety during quarantine, but only $3 \%$ had persistent anxiety at 4 6 months after release. Risk factors for anxiety included inadequate supplies, somatic symptoms related to MERS, financial loss, social media use, and a history of psychiatric illness [21].

\section{Ebola}

The 2014-2016 Ebola outbreak in West Africa spread rapidly due to inadequate healthcare facilities, lack of trained staff, and poor health literacy, leading to inability to receive care from HCWs who were often exposed to and contracted the disease. One year after onset in Sierra Leone, a study on the mental health impact on the general population revealed a prevalence of almost $50 \%$ of any anxiety or depression symptoms via Patient Health Questionnaire-4 (PHQ-4). Prevalence of any PTSD symptom was $76 \%$, as measured by six items from the Impact of Events Scale revised. Of note, only $6 \%$ met the clinical cut-off for anxiety and depression. For PTSD, 27\% met levels of clinical concern, and 16\% met probable diagnosis. Factors associated with higher reporting of symptoms included region of residence, experiences with Ebola such as knowing someone quarantined, and perceived threat [22].

The outbreak reached Spain, the UK, and the USA as a result of globalization and international travel, threatening global security and the world economy. In late 2014, the US military sent 3000 troops to West Africa to help curb this epidemic. A review examining the potential psychological impact of this deployment qualitatively predicted that deployed service members would return with clinically significant problems, including psychological distress, alcohol/drug use, post-traumatic stress disorder, anxiety, and most significantly depression. They also suggested that among militaryspecific sociodemographic factors (young, single, no family, less work experience, lower educational levels and income) predicted poorer outcomes [23].

The second deadliest Ebola outbreak was in 2018 and is currently ongoing. As a result, in the Democratic Republic of the Congo, mental health professionals have joined response teams to provide psychological treatments to patients dealing with anxiety and death [24]. A systematic review of the prevalence of mental health problems in populations affected by the outbreak revealed that approximately $20 \%$ of individuals exposed to the virus (survivors, families, communities, healthcare workers, safe and dignified burial teams) were diagnosed with depression [25].

\section{COVID-19}

On May 13, 2020, the United Nations (UN) policy brief on "COVID-19 and the Need for Action on Mental Health" noted concerns over widespread psychological distress, referencing three sources [26]. The first was a study in China claiming to be the first nationwide large-scale survey of psychological distress in the general population. In total, 52,730 responses to a self-reported questionnaire sought to identify demographic characteristics associated with higher distress levels. The authors suggested that the country's response to the COVID19 pandemic, including implementation of strict quarantine measures, triggered a wide variety of psychological problems, such as panic disorder, anxiety, and depression [27•]. The second was a study in Iran that used the same survey as above. Based on 1058 responses, the authors concluded that predictors of distress may vary across countries, citing differences in age and education that predicted distress in China but not in Iran (younger age and higher education correlated with higher distress in China) [28•].

The third was a survey from April 2020 by the Kaiser Family Foundation revealing that $56 \%$ of adults in the USA believed the pandemic had affected their mental health. Of note, $13 \%$ reported increasing alcohol or drug use. Sixtyfour percent of those who reported stress and worry around COVID-19 come from front-line HCWs and their families and 65\% from Americans who experienced an income loss [29]. As recently as late June, $40 \%$ of US adults reported struggling with mental health issues or substance use, with $31 \%$ endorsing anxiety/depressive symptoms, $26 \%$ endorsing traumarelated symptoms, $13 \%$ endorsing starting or increasing substance use, and $11 \%$ seriously considering suicide [30••].

In China, the immediate psychological effects of the COVID-19 outbreak were more specifically studied in the general population. Using the Impact of Event ScaleRevised (IES-R), 53.8\% reported moderate or severe psychological impact. Using the Depression, Anxiety and Stress Scale (DASS-21), 28.8\% had moderate to severe anxiety symptoms, $16.5 \%$ had moderate to severe depressive symptoms, and $8.1 \%$ had moderate to severe stress levels. Notably, specific physical symptoms such as myalgia, dizziness, cory$\mathrm{za}$, and poor self-rated health status were significantly associated with a greater psychological impact of the outbreak and higher levels of stress, anxiety, and depression [31 ${ }^{\bullet}$. Another similar study in the general population on generalized anxiety disorder (GAD) symptoms, depressive symptoms, and sleep quality revealed similar findings. Results showed that the 
overall prevalence of anxiety symptoms (using Generalized Anxiety Disorder 7-item score $>9$ ) was $35.1 \%$, depressive symptoms $20.1 \%$, and poor sleep quality $18.2 \%$. Of note, they also found that HCWs were more likely to have poor sleep quality than the general population [32•]. Further, in a study of $1257 \mathrm{HCWs}$ in multiple regions of China, 50\% reported symptoms of depression, $45 \%$ anxiety, 34\% insomnia, and $72 \%$ distress [33•]. Reviews of studies on the psychological stress experienced by front-line HCWs during recent pandemics support current COVID-19 data on distress in HCWs $[34 \cdot, 35 \bullet$.

\section{Children}

Results from previous pandemics were limited and did not explore the effect of quarantine on children and families. However, initial data from the COVID-19 pandemic has shown a detrimental effect of quarantine on children. A survey of 1784 primary school students (grades 2-6) in the Hubei province of China during lockdown measures found that $22.6 \%$ reported depressive symptoms and $18.9 \%$ reported anxiety [36•]. In Shanghai, 241 parents of children with attention-deficit/hyperactivity disorder (ADHD) aged 6-15 reported that their behaviors were significantly worse during lockdown [37•]. Among 8079 Chinese students aged 12-18, prevalence of depressive and anxiety symptoms were $43.7 \%$ and $37.4 \%$, respectively, with risk factors including female gender, higher grade level, and lower self-assessed knowledge of COVID-19 [38•].

\section{Discussion}

Published data regarding mental health sequelae from recent pre-COVID-19 pandemics is limited. Most studies have used broad-sweeping inventories of distress and psychological symptoms instead of specific diagnostic screening instruments. Very few prospective clinical trials appear to have been published, and the few reasonably well-constructed retrospective trials had relatively small study populations. Reported outcomes included vague, qualitative entities such as stress, anxiety, panic, worry, exhaustion, emotional disturbance, PTSD symptoms, depressive symptoms, poor sleep quality, increased alcohol use, and behavior problems. Additionally, the fast-moving nature of the pandemic, combined with the challenge of getting behavioral health protocols rapidly approved by institutional review boards, has likely contributed to the scarcity of COVID-19-related outcome data. Given these limitations, we found it difficult to predict with certainty which types of mental health problems are likely to result from COVID-19. However, several general trends and observations are worth noting and may provide some preliminary assistance to medical planners responsible for anticipating the psychological sequelae of COVID-19.

\section{How COVID-19 Observations Compare With Data From Past Pandemics}

The data above is consistent with what we already know about the mental health impacts after a disaster: a significant number of people will experience increased stress during the incident, but the majority will not have lasting psychological sequelae. While this is an important perspective, there are also several differences between past pandemics and the current situation. COVID-19 appears to be more similar to influenza outbreaks than to previous coronavirus infections, with respect to high infectivity, low fatality rates, and a high percentage of asymptomatic infections [39]. From a mental health standpoint, these conditions have the potential to lead to significant anxiety over whether one has the virus and could be unknowingly passing it on to their loved ones.

Compared with other recent pandemics, COVID-19 has considerably more cases with global spread, causing significant impact on daily lives. No other outbreak in recent history has caused such devastating economic distress or the mass closure of businesses. Furthermore, the sheer number of patients infected and HCWs exposed could cause significant strain on the mental healthcare system, even if the majority of people affected do well in the long term. With cases continuing to surface, there is still a great degree of uncertainty regarding the final impact this pandemic will have, including when a vaccine will be developed and how long social distancing precautions will need to continue. These additional factors may lead to more severe psychosocial distress and unanticipated psychiatric disease than has been observed in previous pandemics.

\section{Children}

Data on the effects of the COVID-19 pandemic on children and families are currently limited. However, experts anticipate that all families, regardless of whether family members include patients or HCWs, will be affected due to disruption of the family structure by closures of schools, financial uncertainty, and possible unemployment [40]. While mental health professionals attempt to forecast and implement effective treatment for the most vulnerable populations, much is unknown about the long-term mental health effects of largescale disease outbreaks on children, adolescents, and families. Evolving data suggests that the greatest risks among these populations will include increased anxiety regarding school and work closures, decreased social and community networks, increased pressure on parents to work from home while providing supervision and distance learning, violence when locked in with abusive family members, and unemployment 
potentially leading to loss of essentials, starvation, and homelessness.

\section{Planning Implications}

With numerous predictions and peer-reviewed data emerging about the mental health consequences of COVID-19, one may conclude that healthcare systems and providers must simply anticipate increased demand for all types of psychiatric conditions. However, the information presented above does suggest certain trends that may inform planning more specifically.

First and foremost, several studies noted that individuals' levels of anxiety were indirectly correlated with the degree of communication they received about the virus. Mental health providers, and particularly those trained in the military as command consultants, are uniquely suited to prepare evidence-based communication tools for patients and fellow clinicians, as well as for community leaders hoping to minimize social panic. Such tools should cover what is known about transmission of the virus, for example, how individuals are likely to be infected, what mitigation strategies are most effective, how they should be employed, who is at highest risk for the worst outcomes, who is at greatest risk for psychiatric sequelae, and how mental health may be optimized among affected individuals. Communication also includes providing subject matter expertise to medical and community leaders. Mental health providers should not wait to be asked; they should prepare succinct talking points and intermittently remind public officials and other senior leaders of the most prominent fears fueling anxiety in the community. Additionally, it is important to offer practical and viable suggestions or solutions; providers who present leaders with concerns without solutions will rapidly lose favor with the same individuals they are hoping to influence.

Second, the aforementioned studies found excessive worry and distress about various COVID-related issues. Although there are scores of evidence-based interventions likely to be useful for anxiety and depression, two widely available strategies can address both problems effectively, when used in those identified to be appropriate for treatment: cognitive behavioral therapy (CBT) and antidepressant medications [41-43].

Third, post-traumatic stress symptoms were surprisingly prevalent across pandemics and among numerous demographic groups, suggesting that interventions proven to be effective for PTSD may be a worthy investment of training dollars and clinical resources. Traditional, 10-12 session manualized treatments using prolonged exposure, cognitive processing therapy, and eye movement desensitization and reprocessing are likely to be effective [44-46]. However, recent data suggests that interpersonal therapy, written exposure therapy (WET), strategically dosed propranolol, and mantram repetition may be equally effective and easier to facilitate via telehealth [47-50]. Generally, individual psychotherapy has been shown to be more effective than group-based interventions or medications alone for PTSD [51]. However, in areas where resources are limited, group-based interventions in which cohorts with similar backgrounds can process their experiences together (i.e., front-line workers, COVID-19 survivors, unemployed individuals) may be clinically beneficial. Treating PTSD may also improve insomnia, a symptom of PTSD, that was noted to be prevalent in several of the pandemic-related studies cited above.

Fourth, most responses seen in children during COVID-19 and previous pandemics tend to fall into two major categories - anxiety and restless/disruptive behavior. Since the latter can be a manifestation of the former, planning ways to address anxiety in children is likely to be the best investment of limited clinical resources. Researchers at the Yale University recently demonstrated that coaching for parents in how to manage their anxious children can be as effective as individual CBT conducted with the children themselves [52]. Children may also benefit from individual- or groupbased therapy, especially if they are focused on practical matters, such as how to be good siblings, how to prevent the spread of COVID-19, and ways to burn off energy that accumulates during isolation.

Fifth, although entrepreneurs are rapidly adapting their business models to accommodate infection control measures, sustained high unemployment rates and economic depression appear unavoidable. Historically, financial crises heighten emotional despair and increase rates of suicide [53, 54]. The extent to which COVID-19 will be associated with these impacts is unknown, although some models predict that up to $42 \%$ of jobs lost during COVID will be permanent [55]. Planning for the psychological needs of individuals facing economic devastation is challenging. Not only is there stigma in acknowledging one's financial situation, but the very nature of the problem itself creates a barrier to accessing treatment. The best planning for these outcomes will likely involve nontraditional approaches, such as partnering with community leaders to educate them about the psychological impact of unemployment, getting the word out about available food and shelter, and creating per diem jobs and apprenticeship opportunities. Free support groups and training seminars on topics such as unemployment rights, resume building, and civil service opportunities are likely to make a greater impact than psychotherapy in this population.

Finally, COVID-19 has created many additional psychological problems not widely emphasized among available data, including domestic violence and child abuse. While physical distancing at home is necessary to prevent the spread of disease, social isolation is also a major tactic used by perpetrators of domestic abuse. Strict requirements to maintain isolation may allow perpetrators to gain control by generating guilt in their victims [56]. Isolation from friends, family, and 
employment plays a role as fewer contacts means fewer people to recognize abuse and provide assistance. Typically, $20 \%$ of reports to child protective services come from educators [57]. Because schools and other childcare facilities are closed, families at risk are not likely getting the resources or referrals they need. Both substance misuse and domestic abuse are likely to be underreported, yet they are of critical significance.

Additionally, many minority populations and lowerincome front-line workers are at risk for greater exposure to COVID-19, greater risk of developing serious medical sequelae, lower likelihood of insurance coverage, and increased institutional bias that may negatively impact their course of treatment [58]. Providers and medical staff who regularly care for these populations should be reminded of the risks incurred by these vulnerable populations and utilized to train their medical peers on how to screen at-risk patients, as well as how to optimize patient access to treatment resources and shelters. There have also been many accounts of discriminatory behaviors against Asian Americans and Pacific Islanders (AAPI) since the COVID-19 outbreak [59, 60]. It is now widely known that in general, the experience of racial discrimination is a determinant of poor mental health [61-63]. Thus, it is important for providers to be aware of these experiences and anticipate increases in the secondary effects of discrimination, such as psychological trauma, anxiety, and depression in these populations. Lastly, bereavement will unquestionably be a significant consequence of COVID-19, yet available literature from COVID-19 and past pandemics is remarkably void of data on grief and bereavement [64].

\section{Conclusion}

The COVID-19 pandemic has changed the landscape of behavioral health dramatically. Expanded telehealth capabilities have increased our ability to reach those suffering and provide better patient-centered care, yet these new care delivery systems are not ubiquitously available. Furthermore, testing these capabilities may be a trial by fire if predictions about a looming mental health crisis prove accurate. It is therefore important to focus planning efforts on interventions likely to have the greatest impact. Evidence-based treatments for PTSD, anxiety, and depression, particularly those more easily delivered using virtual platforms, should become the standard post-COVID toolkit for behavioral health clinicians. Groupbased interventions will also be critical, particularly for parents, children, and cohorts of similarly impacted individuals, to decrease isolation, normalize experiences, and promote emotional validation. Simply being able to direct suffering individuals to support groups and self-help/educational resources may be as impactful as traditional behavioral health interventions. Such community-based support is widely used in the American military and is consistent with the doctrinal principles of military disaster response [65]. This analysis was based on peer-reviewed and non-peer-reviewed scholarly reports, many of which were of limited quality and frequently retrospective in nature. Additionally, much of the COVID-19 data is still in pre-print form as of this writing. Our rapid review of the existing literature was intended to provide military and civilian mental health planners with timely, actionable data to help guide their decisions regarding staff training and resource allocation. However, we acknowledge that our rapid method of review may have excluded some informative publications that would have been identified if we had used a full PRISMA systematic review. Future research on planning and response to post-pandemic mental health demands should be based on prospective, randomized, controlled, peerreviewed data whenever possible. It is our hope that research will continue into the ongoing psychological impact of COVID-19.

\section{Compliance with Ethical Standards}

Disclaimer The views expressed in this manuscript are those of the author and do not reflect the official policy of the Department of Army/Navy/Air Force, Department of Defense, or US Government.

\section{References}

Papers of particular interest, published recently, have been highlighted as:

- Of importance

•• Of major importance

1. Torres-Salinas D. Ritmo de crecimiento diario de la producción científica sobre Covid-19. Análisis en bases de datos y repositorios en acceso abierto [Daily growth rate of scientific production on Covid-19. Analysis in databases and open access repositories]. El profesional de la información. 2020;29(2):1699-2407. Spanish. https://doi.org/10.3145/epi.2020.mar.15

2.• Morganstein JC, Ursano RJ, Fullerton CS, et al. Pandemics: health care emergencies. In: Ursano RJ, Fullerton CS, Weisaeth L, Raphael B, editors. Textbook of Disaster Psychiatry. Cambridge, UK: Cambridge University Press; 2017. p. 270-83. This book chapter reviews the available mental health literature concerning the most impactful global infectious disease outbreaks pre-COVID, and considers focused issues regarding mental health intervention planning for non-specific pandemics.

3.• Preti E, Di Mattei V, Perego G, et al. The psychological impact of epidemic and pandemic outbreaks on healthcare workers: rapid review of the evidence. Curr Psychiatry Rep. 2020;22:43. https:// doi.org/10.1007/s11920-020-01166-z This article reviews the psychological impact of epidemic/pandemic outbreaks specifically on healthcare workers.

4. Calati R, Cohen LJ, Schuck A, et al. The modular assessment of risk for imminent suicide (MARIS): a validation study of a novel tool for suicide risk assessment. J Affect Disord. 2019 [published online December 11, 2019]. https://doi.org/10.1016/j.jad.2019.12. 001. 
5. Oyesanya M, Lopez-Morinigo J, Dutta R. Systematic review of suicide in economic recession. World J Psychiatry. 2015 [published online June 26, 2015]. https://doi.org/10.5498/wjp.v5.i2.243.

6. Grant MJ, Booth A. A typology of reviews: an analysis of 14 review types and associated methodologies, Health Inf Libr J 2009. doi: https://doi.org/10.1111/j.1471-1842.2009.00848.x, [published online May 27, 2009]. A typology of reviews: an analysis of 14 review types and associated methodologies.

7. Reporting guidelines under development for systematic reviews. The EQUATOR Network website and database. Last updated July 2018. https://www.equator-network.org/library/reportingguidelines-under-development/reporting-guidelines-underdevelopment-for-systematic-reviews/\#51. Accessed September 10, 2020.

8. Kelly SE, Moher D, Clifford TJ. Quality of conduct and reporting in rapid reviews: an exploration of compliance with PRISMA and AMSTAR guidelines. Syst Rev. 2016;5:79. https://doi.org/10. 1186/s13643-016-0258-9.

9. McAlonan GM, Lee AM, Cheung V, et al. Psychological morbidity related to the SARS outbreak in Hong Kong. Psychol Med. 2005 [published online April 22, 2005]. https://doi.org/10.1017/ s0033291704004362.

10. Peng EY, Lee MB, Tsai ST, et al. Population-based post-crisis psychological distress: an example from the SARS outbreak in Taiwan. J Formos Med Assoc. 2010 [published online July 27, 2010]. https://doi.org/10.1016/S0929-6646(10)60087-3.

11. Wu P, Liu X, Fang Y, et al. Alcohol abuse/dependence symptoms among hospital employees exposed to a SARS outbreak. Alcohol Alcohol. 2008 [published online September 16, 2008]. https://doi. org/10.1093/alcalc/agn073.

12. Liu X, Kakade M, Fuller CJ, et al. Depression after exposure to stressful events: lessons learned from the severe acute respiratory syndrome epidemic. Compr Psychiatry. 2011 [published online April 15, 2011]. https://doi.org/10.1016/j.comppsych.2011.02.003.

13. Lancee WJ, Maunder RG, Goldbloom DS, et al. Prevalence of psychiatric disorders among Toronto hospital workers one to two years after the SARS outbreak. Psychiatr Serv. 2008 [published online January 10, 2008]. https://doi.org/10.1176/ps.2008.59.1.91.

14. Yip PS, Cheung YT, Chau PH, et al. The impact of epidemic outbreak: the case of severe acute respiratory syndrome (SARS) and suicide among older adults in Hong Kong. Crisis. 2010 [published online April 27, 2010]. https://doi.org/10.1027/0227-5910/ a000015.

15. Leung GM, Quah S, Ho LM, et al. Community psycho-behavioural surveillance and related impact on outbreak control in Hong Kong and Singapore during the SARS epidemic. Hong Kong Med J. 2009;15(Suppl 9):30-4.

16. Mak IW, Chu CM, Pan PC, et al. Long-term psychiatric morbidities among SARS survivors. Gen Hosp Psychiatry. 2009 [published online June 27, 2009]. https://doi.org/10.1016/j.genhosppsych. 2009.03.001

17. Pfefferbaum B, Schonfeld D, Flynn BW, et al. The H1N1 crisis: a case study of the integration of mental and behavioral health in public health crises. Disaster Med Public Health Prep. 2012 [published online April 12, 2012]. https://doi.org/10.1001/dmp.2012.2.

18. Gu J, Zhong Y, Hao Y, et al. Preventive behaviors and mental distress in response to H1N1 among university students in Guangzhou, China. Asia Pac J Public Health. 2012 [published online April 27, 2012]. https://doi.org/10.1177/1010539512443699.

19. Goulia P, Mantas C, Dimitroula D, et al. General hospital staff worries, perceived sufficiency of information and associated psychological distress during the $\mathrm{A} / \mathrm{H} 1 \mathrm{~N} 1$ influenza pandemic. BMC Infect Dis. 2010 [published online November 11, 2010]. https://doi. org/10.1186/1471-2334-10-322.

20. Matsuishi K, Kawazoe A, Imai H, et al. Psychological impact of the pandemic (H1N1) 2009 on general hospital workers in Kobe.
Psychiatry Clin Neurosci. 2012 [published online May 26, 2012]. https://doi.org/10.1111/j.1440-1819.2012.02336.x.

21. Jeong H, Yim HW, Song YJ, et al. Mental health status of people isolated due to Middle East Respiratory Syndrome. Epidemiol Health. 2017 [published online February 16, 2017]. https://doi. org/10.4178/epih.e2016048.

22. Jalloh MF, Li W, Bunnell RE, et al. Impact of Ebola experiences and risk perceptions on mental health in Sierra Leone, July 2015. BMJ Glob Health. 2018 [published online April 3, 2018]. https:// doi.org/10.1136/bmjgh-2017-000471.

23. Vyas KJ, Delaney EM, Webb-Murphy JA, et al. Psychological impact of deploying in support of the U.S. response to Ebola: a systematic review and meta-analysis of past outbreaks. Mil Med. 2016 [published online November 17, 2016]. https://doi.org/10. 7205/MILMED-D-15-00473.

24. Cenat JM, Balayulu-Makila O, Derivois D, et al. The mental health professional at the feet of the Ebola virus: individual treatment and global mental challenges. Br J Psychiatry. 2019 [published online May 31, 2019]. https://doi.org/10.1192/bjp.2019.122.

25. Cenat JM, Felix N, Blais-Rochette C, et al. Prevalence of mental health problems in populations affected by the Ebola virus disease: a systematic review and meta-analysis. Psychiatry Res. 2020 [published online May 11, 2020]. https://doi.org/10.1016/j.psychres. 2020.113033.

26. Policy Brief: COVID-19 and the need for action on mental health. United Nations website. https://www.un.org/sites/un2.un.org/files/ un_policy_brief-covid_and_mental_health_final.pdf. Published May 13, 2020. Accessed May 28, 2020.

27. Qiu J, Shen B, Zhao M, et al. A nationwide survey of psychological distress among Chinese people in the COVID-19 epidemic: implications and policy recommendations. Gen Psychiatr. 2020. https:// doi.org/10.1136/gpsych-2020-100213 [published online March 28, 2020]. This study claims to be the first nationwide large-scale survey of psychological distress in the general population of China during the COVID-19 epidemic.

28. Jahanshahi AA, Dinani MM, Madavani AN, et al. The distress of Iranian adults during the Covid-19 pandemic - More distressed than the Chinese and with different predictors. Brain Behav Immun. 2020. https://doi.org/10.1016/j.bbi.2020.04.081 [published online May 4, 2020]. This study claims to be the first to provide empirical evidence of distress amongst Iranian adults that is more significant than in China during the COVID-19 pandemic.

29. Kirzinger A, Hamel, L, Muñana, C, Kearney, A, Brodie, M. KFF Health Tracking Poll - Late: Coronavirus, Social Distancing, and Contact Tracing Kaiser Family Foundation website 2020 https:// wwwkfforg/report-section/kff-health-tracking-poll-late-april-2020economic-and-mental-health-impacts-of-coronavirus/ Published April 24, 2020. Accessed May 27, 2020.

30.• Czeisler MÉ, Lane RI, Petrosky E, et al. Mental health, substance use, and suicidal ideation during the COVID-19 pandemic United States, June 24-30, 2020. MMWR Morb Mortal Wkly Rep. 2020;69:1049-57. https://doi.org/10.15585/mmwr.mm6932a This report reveals the demographics of U.S. adults disproportionately affected by COVID-19.

31. Wang C, Pan R, Wan X, et al. Immediate psychological responses and associated factors during the initial stage of the 2019 coronavirus disease (COVID-19) epidemic among the general population in China. Int J Environ Res Public Health. 2020. https://doi.org/10. 3390/ijerph17051729 [published online March 12, 2020]. This study identifies various factors, including information dissemination, associated with a lower level of psychological impact and better mental health status.

32. Huang Y, Zhao N. Generalized anxiety disorder, depressive symptoms and sleep quality during COVID-19 outbreak in China: a webbased cross-sectional survey. Psychiatry Res. 2020. https://doi.org/ 
10.1016/j.psychres.2020.112954 [published online April 24, 2020]. This study identifies a major mental health burden of the public during the COVID-19 outbreak, and healthcare workers at high risk for poor sleep.

33. Lai J, Ma S, Wang Y, et al. Factors associated with mental health outcomes among health care workers exposed to coronavirus disease 2019. JAMA Netw Open. 2020. https://doi.org/10.1001/ jamanetworkopen.2020.3976 [published online March 24, 2020]. This study demonstrates women, nurses, those in Wuhan, and front-line healthcare workers as high risk of developing unfavorable mental health outcomes, needing psychological support or interventions.

34. Bohlken J, Schomig F, Lemke MR et al. COVID-19 pandemic: stress experience of healthcare workers - a short current review. Psychiatr Prax [published online April 28, 2020]. doi: https://doi. org/10.1055/a-1159-5551. This article reviews the psychological stress of healthcare workers caused by the COVID-19 pandemic.

35. Kisely S, Warren N, McMahon L et al. Occurrence, prevention, and management of the psychological effects of emerging virus outbreaks on healthcare workers: rapid review and meta-analysis. BMJ [published online May 7, 2020]. doi: https://doi.org/10. 1136/bmj.m1642. This article reviews the psychological effects on clinicians of working to manage novel viral outbreaks, and successful measures to manage stress and psychological distress.

36. Xie X, Xue Q, Zhou Y et al. Mental health status among children in home confinement during the coronavirus disease 2019 outbreak in Hubei Province, China. JAMA Pediatr [published online April 25, 2020]. doi: https://doi.org/10.1001/jamapediatrics.2020.1619. This study investigates depressive and anxiety symptoms among students in Hubei province, China, during the outbreak of COVID-19.

37. Zhang J, Shuai L, Yu H et al. Acute stress, behavioural symptoms and mood states among school-age children with attention-deficit/ hyperactive disorder during the COVID-19 outbreak. Asian J Psychiatr [published online April 22, 2020]. doi: https://doi.org/ 10.1016/j.ajp.2020.102077. This study illustrates that during the COVID-19 outbreak in Shanghai children's ADHD symptoms were significantly worse compared to normal state.

38. Zhou SJ, Zhang LG, Wang LL, et al. Prevalence and sociodemographic correlates of psychological health problems in Chinese adolescents during the outbreak of COVID-19. Eur Child Adolesc Psychiatry. 2020. https://doi.org/10.1007/s00787020-01541-4 [published online May 5, 2020]. This study shows a high prevalence of psychological health problems among Chinese adolescents, which are negatively associated with the level of awareness of COVID-19.

39. Day M. Covid-19: four fifths of cases are asymptomatic, China figures indicate. BMJ. 2020 [published online April 4, 2020]. https://doi.org/10.1136/bmj.m1375.

40. Morganstein JC. Preparing for a marathon: healthcare worker and organizational sustainment during COVID-19. Presented virtually at the American Psychiatric Association Spring Highlights 2020 meeting 2020. https://vimeo.com/411879284/c1c50ed142. Published April 25, 2020. Accessed June 5, 2020.

41. Flynn HA, Warren R. Using CBT effectively for treating depression and anxiety. Current Psychiatry website 2020. https://www. mdedge.com/psychiatry/article/82695/anxiety-disorders/using-cbteffectively-treating-depression-and-anxiety. Published June 2014. Accessed September 11, 2020.

42. First-choice antidepressant use in adults with depression or generalised anxiety disorder. NICE Anxiety website. https://www.nice. org.uk/advice/ktt8. Published January 15, 2015. Accessed June 5, 2020.
43. Common mental health problems: identification and pathways to care. NICE Anxiety website. https://www.nice.org.uk/guidance/ cg123. Published May 25, 2011. Accessed June 5, 2020.

44. Resick PA, Nishith P, Weaver TL, et al. A comparison of cognitiveprocessing therapy with prolonged exposure and a waiting condition for the treatment of chronic posttraumatic stress disorder in female rape victims. J Consult Clin Psychol. 2002 [published online August 17, 2002]. https://doi.org/10.1037//0022-006x.70.4.867.

45. Foa EB, Hembree EA, Cahill SP, et al. Randomized trial of prolonged exposure for posttraumatic stress disorder with and without cognitive restructuring: outcome at academic and community clinics. J Consult Clin Psychol. 2005 [published online November 17, 2005]. https://doi.org/10.1037/0022-006X.73.5.953.

46. Shapiro F, Maxfield L. Eye movement desensitization and reprocessing (EMDR): information processing in the treatment of trauma. J Clin Psychol. 2002 [published online July 13, 2002]. https://doi.org/10.1002/jclp.10068.

47. Bormann JE, Thorp SR, Smith E, et al. Individual treatment of posttraumatic stress disorder using mantram repetition: a randomized clinical trial. Am J Psychiatry. 2018 [published online June 21, 2018]. https://doi.org/10.1176/appi.ajp.2018.17060611.

48. Brunet A, Saumier D, Liu A, et al. Reduction of PTSD symptoms with pre-reactivation propranolol therapy: a randomized controlled trial. Am J Psychiatry. 2018 [published online January 13, 2018]. https://doi.org/10.1176/appi.ajp.2017.17050481.

49. Markowitz JC, Petkova E, Neria Y, et al. Is exposure necessary? A randomized clinical trial of interpersonal psychotherapy for PTSD. Am J Psychiatry. 2015 [published online February 14, 2015]. https://doi.org/10.1176/appi.ajp.2014.14070908.

50. Sloan DM, Marx BP, Lee DJ, et al. A brief exposure-based treatment vs cognitive processing therapy for posttraumatic stress disorder: a randomized noninferiority clinical Trial. JAMA Psychiatry. 2018 [published online January 19, 2018]. https://doi.org/10.1001/ jamapsychiatry.2017.4249.

51. VA/DOD clinical practice guideline for the management of posttraumatic stress disorder and acute stress reaction 2017. Department of Veterans Affairs website. https://www.healthquality.va.gov/ guidelines/MH/ptsd/. Accessed June 5, 2020.

52. Lebowitz ER, Marin C, Martino A, et al. Parent-based treatment as efficacious as cognitive-behavioral therapy for childhood anxiety: a randomized noninferiority study of supportive parenting for anxious childhood emotions. J Am Acad Child Adolesc Psychiatry. 2019 [published online March 10, 2019]. https://doi.org/10.1016/ j.jaac.2019.02.014.

53. Chan $\mathrm{CH}$, Caine $\mathrm{ED}$, You $\mathrm{S}$, et al. Suicide rates among working-age adults in South Korea before and after the 2008 economic crisis. J Epidemiol Community Health. 2013 [published online November 20, 2013]. https://doi.org/10.1136/jech-2013-202759.

54. Phillips JA, Nugent CN. Suicide and the great recession of $2007-$ 2009: the role of economic factors in the 50 U.S. states. Soc Sci Med. 2014 [published online June 29, 2014]. https://doi.org/10. 1016/j.socscimed.2014.06.015.

55. Milner A, Morrell S, LaMontagne AD. Economically inactive, unemployed and employed suicides in Australia by age and sex over a 10-year period: what was the impact of the 2007 economic recession? Int J Epidemiol. 2014 [published online July 30, 2014]. https://doi.org/10.1093/ije/dyu148.

56. Taub A. A new Covid-19 crisis: domestic abuse rises worldwide. The New York Times 2020. https://www.nytimes.com/2020/04/06/ world/coronavirus-domestic-violence.html. Published April 6, 2020. Accessed May 28, 2020.

57. Child maltreatment 2018. U.S. Department of Health \& Human Services Children's Bureau website 2020. https://www.acf.hhs. gov/cb/resource/child-maltreatment-2018. Published January 15, 2020. Accessed May 28, 2020. 
58. Garg S, Kim L, Whitaker M, et al. Hospitalization rates and characteristics of patients hospitalized with laboratory-confirmed coronavirus disease 2019 - COVID-NET, 14 States, March 1-30, 2020. MMWR Morb Mortal Wkly Rep. 2020; https://www.cdc. gov/mmwr/volumes/69/wr/mm6915e3.htm. Published April 17, 2020. Accessed June 5, 2020.

59. Reports of anti-Asian assaults, harassment and hate crimes rise as coronavirus spreads. Anti-Defamation League website. https:// www.adl.org/blog/reports-of-anti-asian-assaults-harassment-andhate-crimes-rise-as-coronavirus-spreads. Published May 27, 2020. Accessed May 28, 2020.

60. Jeung R, Nham K. Incidents of coronavirus-related discrimination. Asian Pacific Policy \& Planning Council 2020. http://www. asianpacificpolicyandplanningcouncil.org/wp-content/uploads/ STOP_AAPI_HATE_MONTHLY_REPORT_4_23_20.pdf. Published April 23, 2020. Accessed May 28, 2020.

61. Paradies Y, Ben J, Denson N, et al. Racism as a determinant of health: a systematic review and meta-analysis. PLoS One. 2015 [published online September 24, 2015]. https://doi.org/10.1371/ journal.pone.0138511.

62. Shim RS, Compton MT. The social determinants of mental health: psychiatrists' roles in addressing discrimination and food insecurity. Focus (Am Psychiatr Publ). 2020. https://doi.org/10. 1176/appi.focus.20190035 [published online February 13, 2020].

This article nicely describes the social determinants of mental health, including discrimination and food insecurity.

63. Wallace S, Nazroo J, Becares L. Cumulative effect of racial discrimination on the mental health of ethnic minorities in the United Kingdom. Am J Public Health. 2016 [published online April 15, 2016]. https://doi.org/10.2105/AJPH.2016.303121.

64. Mayland CR, Harding AJE, Preston N, Payne S. Supporting adults bereaved through COVID-19: a rapid review of the impact of previous pandemics on grief and bereavement. J Pain Symptom Manag. 2020;60:e33-9. https://doi.org/10.1016/j.jpainsymman. 2020.05.012.

65. United States. Department of the Army. The U.S. Army/Marine Corps Counterinsurgency Field Manual: U.S. Army Field Manual No. 3-24 : Marine Corps Warfighting Publication No. 3-33.5. Chicago: University of Chicago Press, 2007

Publisher's Note Springer Nature remains neutral with regard to jurisdictional claims in published maps and institutional affiliations. 